\title{
DESIGN CENTRADO NO USUÁRIO: REQUISITOS PARA AVALIAÇÃO DE PRODUTOS DURANTE O DESENVOLVIMENTO DE PROJETOS COM BASE NA USABILIDADE E DESIGN UNIVERSAL
}

\author{
USER CENTERED DESIGN: REQUIREMENTS FOR THE EVALUATION \\ OF PRODUCTS DURING THE PROJECTS DEVELOPMENT \\ PROCESS BASED ON USABILITY AND UNIVERSAL DESIGN
}

\author{
Lucas José Garcia ${ }^{1}$, M.Sc. \\ Giselle Schmidt Alves Diaz Merino², D.Sc \\ Eugenio Andrés Díaz Merino ${ }^{3}$, DSc \\ (1) Universidade Federal de Santa Catarina (UFSC) \\ e-mail: lucasjose@gmail.com \\ (2) Universidade Federal de Santa Catarina (UFSC) \\ Universidade do Estado de Santa Catarina (UDESC) \\ e-mail: gisellemerino@gmail.com \\ (3) Universidade Federal de Santa Catarina (UFSC) \\ e-mail: eugenio.merino@ufsc.br
}

Palavras-chave: Desenvolvimento de Produto, Ergonomia, Requisitos

Este artigo aborda a criação de requisitos para o desenvolvimento e avaliação de produtos, em diferentes estágios de desenvolvimento, com base em princípios de Usabilidade e do Design Universal, dentro de uma abordagem metodológica embasada no Design Centrado no Usuário. Como resultados foram gerados e descritos requisitos que permitem avaliar produtos e assim gerar propostas mais inclusivas e funcionais.

Key-words: Product Development, Ergonomics, Requirements

This article deals with the creation of requirements for the evaluation of products at different stages of development, based on Usability and Universal Design principles, within a methodological approach based on User Centered Design. As a result, the requirements were generated and described. Thus, contributing to product evaluation and the generation of more inclusive and functional proposals. 


\section{$16^{\circ}$ \\ ERGODESIGN USIHC CINAHPA}

\section{Introdução}

Embora os produtos facilitem as tarefas do dia a dia e melhorem a qualidade de vida das pessoas, estes também podem causar experiências ruins como acidentes, desconforto e fadiga (VINK, 2007, VINK, 2016). Ainda que existam produtos com foco na simplicidade e facilidade de uso, para Hosking, Clarkson e Coleman (2014), o avanço da tecnologia tem resultado em produtos com cada vez mais recursos, botões, mostradores e códigos necessários ao seu funcionamento. Essa variedade de opções pode saturar a atenção do usuário, $\mathrm{e}$ consequentemente, gerar dificuldades de acesso e utilização das funções básicas do produto.

O desenvolvimento de produtos com ênfase nos usuários converge para temas como Ergonomia (GOMES FILHO, 2010; IIDA; GUIMARÃES, 2016), Usabilidade (ISO 9241-11, 2010, JORDAN et al., 1998; PREECE, ROGERS, SHARP, 2005), Design Universal (MACE; HARDIE; PLACE, 1996; CONNELL et al., 1997; CAMBIAGHI, 2012; CHISHOLM; MAY, 2008), Design Inclusivo (COLEMAN et al., 2014; HOSKING; WALLER, 2014; WALLER; CLARKSON, 2016) e Design Centrado no Usuário, utilizado nesta pesquisa como sinônimo de Projeto Centrado no Ser Humano (ISO 9241-210, 2011). Apesar destes temas apresentarem propostas para tornar os produtos mais fáceis de usar, inclusivos e funcionais, nem sempre podem ser implementados no desenvolvimento de produtos. Para HallAndersen e Broberg (2013) isso ocorre pois quando os requisitos ergonômicos de um produto são repassados para a equipe de design, esses têm dificuldade de implementa-los no projeto e em muitos casos o resultado é insatisfatório. Como solução os autores sugerem a maior integração entre as áreas para facilitar o design ergonômico.

O Design Centrado no Usuário pode ser uma alternativa para viabilizar a aproximação designerusuário. Por meio de testes com usuários, em diferentes estágios de desenvolvimento do produto, é possível testar as soluções ergonômicas e corrigir possíveis lacunas. Para tanto, é importante saber que requisitos avaliar no produto. Diante deste $16^{\circ}$ Ergodesign - Congresso Internacional de Ergonomia e Usabilidade de Interfaces Humano Tecnológica: Produto, Informações Ambientes Construídos e Transporte

$16^{\circ}$ USIHC - Congresso Internacional de Ergonomia e Usabilidade de Interfaces Humano Computador

CINAHPA | 2017 - Congresso Internacional de Ambientes Hipermídia para Aprendizagem. cenário, este trabalho tem como objetivo apresentar requisitos para avaliação de produtos, durante o processo de desenvolvimento de projetos, com base na Usabilidade e no Design Universal.

Ainda que o pensamento ergonômico possa auxiliar o desenvolvimento de projetos no Design, no Brasil, o uso de dados dos usuários para a correta adequação usuário-produto ainda é pouco utilizado. Acredita-se que isso aconteça por razões como: falta de conscientização da importância do assunto por parte dos profissionais da área e por parte dos educadores das instituições de ensino superior e; falta de conhecimento geral, uma vez que a Ergonomia é relativamente recente, e até o ano de 2010, não havia sido implementada em todos os programas curriculares dos cursos de Design (GOMES FILHO, 2010). Somado a isto, Merino (2014) expõe que o Design Universal além de ser um tema recente no país é um tema incomum no meio acadêmico e profissional.

\section{Fundamentação Teórica}

\subsection{Design Centrado no Usuário}

O Design Centrado no Usuário teve início na década de 50, durante a mudança de paradigma da era industrial para a era dos produtos como bens de consumo (KRIPPENDORFF, 2000). Mesmo tendo início na década de 50, pode ser considerado um tema recente, haja visto que tem sua sistemática incorporada em abordagens mais recentes como o Design Universal e Design Inclusivo, isso ocorre pois segundo Brown (2010, p. 189) “estamos presenciando uma mudança no equilíbrio de forças, na medida em que as economias evoluem do foco em produtos manufaturados para outro que favorece serviços e experiências. "

O tema compreende uma abordagem que tem base na ergonomia, ciências da computação e inteligência artificial, áreas que também influenciaram a usabilidade. Esses temas formam a base das normas sobre Design Centrado no Ser Humano, explicitados na norma ISO 13407 posteriormente substituída pela norma ISO 9241210 do ano de 2011 (GIACOMIN, 2012). Segundo
Realização:

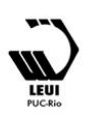




\section{$16^{\circ}$ \\ ERGODESIGN USIHC CINAHPA}

definição da norma ISO 9241-210:

O projeto centrado no ser humano é uma abordagem para o desenvolvimento de sistemas interativos que objetiva tornar os sistemas utilizáveis e úteis, dando ênfase aos usuários, suas necessidades e exigências, pela aplicação de conhecimentos e técnicas de usabilidade e fatores humanos/ergonomia. Esta abordagem aumenta a eficácia e a eficiência, aprimora o bem-estar do ser humano, a satisfação do usuário, a acessibilidade e a sustentabilidade; e neutraliza possíveis efeitos adversos do seu uso na saúde, na segurança e no desempenho (ISO 9241-210, 2011, p. VII).

As considerações do Design Centrado no Usuário no desenvolvimento de projetos de design podem gerar resultados mais satisfatórios tanto para o usuário quanto para as organizações, pois (ISO 9241-210, 2011, p. 4-5):

- Aumentam a produtividade dos usuários e a eficiência operacional das organizações;

- São mais fáceis de entender e utilizar, reduzindo custos de treinamento e suporte;

- Aumentam a usabilidade para as pessoas com uma ampla gama de capacidades, aumentando assim a acessibilidade;

- Melhoram a experiência do usuário;

- Reduzem o desconforto e o estresse;

- Fornecem vantagens competitivas, por exemplo, por meio de melhorias da imagem da marca;

- Contribuem para os objetivos de sustentabilidade.

O uso dessa abordagem ocorre mediante sua incorporação em metodologias de projeto. Suas fases são genéricas e podem utilizar os resultados das etapas de outros métodos. A ideia central desta abordagem consiste em testes com protótipos, ou modelos funcionais, com os usuários ao final das etapas do projeto. A Figura 1, a seguir, apresenta as atividades do Projeto Centrado no Ser Humano (ISO 9241-210, 2011): $16^{\circ}$ Ergodesign - Congresso Internacional de Ergonomia e Usabilidade de Interfaces Humano Tecnológica: Produto, Informações Ambientes Construídos e Transporte

$16^{\circ}$ USIHC - Congresso Internacional de Ergonomia e Usabilidade de Interfaces Humano Computador

CINAHPA | 2017 - Congresso Internacional de Ambientes Hipermídia para Aprendizagem.

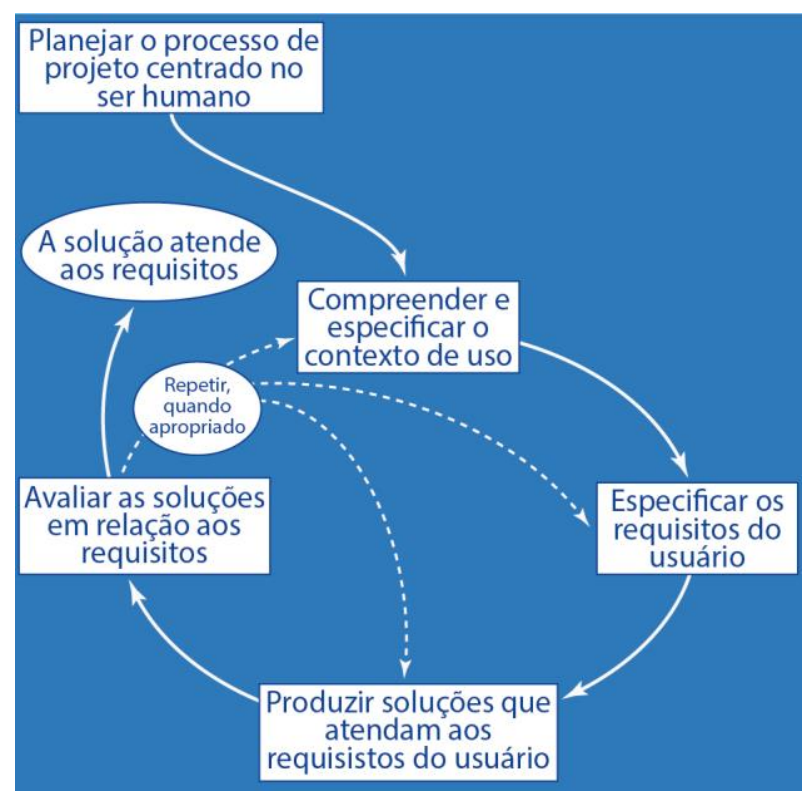

Figura 1: Atividades do Projeto Centrado no Ser Humano. Fonte: ISO 9241-210 (2011).

Enquanto o Design Centrado no Usuário direciona o design para os usuários mediante ações na metodologia de projeto (testes com usuários), a Usabilidade propõe princípios que podem auxiliar no projeto por meio da avaliação direta de produtos, e o Design Universal se propõem a guiar o desenvolvimento de projetos pela avaliação dos produtos segundo seus princípios.

\subsection{Usabilidade}

A Usabilidade destacou-se inicialmente nas décadas de 1970 e 1980, entre os ergonomistas que projetavam computadores e sistemas interativos. Para Jordan et al. (1998), o tema pode ser informalmente definido como a facilidade de utilização de um produto. Segundo Moraes (2001), a Usabilidade trata da adequação produto-tarefa, envolvendo o usuário, o contexto e o ambiente de uso.

No ano de 1998 a Organização Internacional para Padronização (International Standards Organization - ISO) passou a definir Usabilidade em termos de desempenho e satisfação do usuário, considerando Usabilidade a "medida na qual um produto pode ser usado por usuários específicos para alcançar objetivos específicos com eficácia, eficiência e satisfação em um contexto específico 
$16^{\circ}$ Ergodesign - Congresso Internacional de Ergonomia e Usabilidade de Interfaces Humano Tecnológica: Produto, Informações Ambientes Construídos e Transporte

$16^{\circ}$ USIHC - Congresso Internacional de Ergonomia e Usabilidade de Interfaces Humano Computador

CINAHPA | 2017 - Congresso Internacional de Ambientes Hipermídia para Aprendizagem. de uso" (ISO 9241, 2011, p. 3). Jordan et al. (1998) e a norma ISO 9241-11 (2011) apresentam 10 princípios associados à Usabilidade, são eles:

- Consistência: Tarefas similares devem ser possíveis de serem executadas de forma similar;

- Compatibilidade: O método de operação do produto deve ser compatível com as expectativas do usuário, baseado em suas experiências com outros produtos e no mundo exterior;

- Consideração dos Recursos do Usuário: O produto deve ser projetado levando-se em consideração a demanda do produto por recursos do usuário;

- Retroalimentação: Também denominado feedback, considera que as ações realizadas no sistema/produto devem ser indicadas e os resultados devem ter uma apresentação significativa;

- Prevenção de Erros e Recuperação: A possibilidade de erros deve ser minimizada, e caso ocorram, deve haver a possibilidade de serem corrigidas de forma rápida e simples;

- Controle do Usuário: Permitir controle ao usuário para realizar adequações nas ações realizadas pelo produto;

- Clareza Visual: As informações exibidas ao usuário devem ser de rápida leitura e entendimento, sem causar confusão;

- Priorização da Funcionalidade e Informação: As funcionalidades e informações mais importantes devem ser as mais facilmente acessíveis ao usuário;

- Transferência Adequada de Tecnologia: Fazer uso apropriado da tecnologia desenvolvida em outros contextos para aumentar a Usabilidade do produto;

- Explicitude: A utilização do produto deve ser coerente com sua funcionalidade e forma de operação.

\subsection{Design Universal}

O termo Design Universal foi usado pela primeira vez nos Estados Unidos, por um arquiteto chamado Ronald Mace. Esta abordagem se originou das reivindicações de pessoas com deficiência, que não tinham suas necessidades atendidas e, por iniciativa de arquitetos, engenheiros, urbanistas e designers que entendiam a necessidade de incluir todos os indivíduos como potenciais usuários dos produtos, (CAMBIAGHI, 2012). O Design Universal propõe o desenvolvimento de ambientes e produtos com acessibilidade integrada, que possam ser utilizados pelo maior número de pessoas possível, sejam ou não pessoas com deficiência (MACE; HARDIE; PLACE, 1996; LAGATTA, NICOLATONIO, VALLICELLI, 2015).

Connell et al. (1997) criaram 7 princípios que se propõem a guiar os designers na concepção dos projetos e a testar os produtos perante os usuários, para que sejam desenvolvidos produtos e ambientes mais funcionais, são eles:

- Princípio 1 - Uso Equitativo (ou Uso Igualitário): o design é útil e vendável para pessoas com habilidades diversas;

- Princípio 2 - Uso Flexível (ou Uso Adaptável): o design acomoda uma ampla gama de preferências e habilidades individuais;

- Princípio 3 - Uso Simples e Intuitivo: o uso do design é fácil de entender, independentemente da experiência, conhecimento, habilidades de linguagem ou nível de educação do usuário;

- Princípio 4 - Informação de Fácil Percepção: o design comunica informação necessária ao usuário de maneira efetiva, independentemente das condições do ambiente ou das habilidades sensoriais do usuário;

- Princípio 5 - Tolerância ao Erro (ou Uso Seguro): o design minimiza acidentes e as consequências adversas de atitudes acidentais ou não intencionais;

- Princípio 6 - Baixo Esforço Físico (Mínimo Esforço Físico ou, Menor Fadiga): o design
Realização:

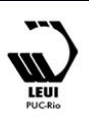




\section{$16^{\circ}$ \\ ERGODESIGN USIHC CINAHPA}

$16^{\circ}$ Ergodesign - Congresso Internacional de Ergonomia e Usabilidade de Interfaces Humano Tecnológica: Produto, Informações Ambientes Construídos e Transporte

$16^{\circ}$ USIHC - Congresso Internacional de Ergonomia e Usabilidade de Interfaces Humano Computador

CINAHPA | 2017 - Congresso Internacional de Ambientes Hipermídia para Aprendizagem. pode ser usado de forma eficiente e confortável e com um mínimo de fadiga;

- Princípio 7 - Dimensão e Espaço para Aproximação e Uso (ou Tamanho e Espaço para Abordagem e Uso): tamanho apropriado e espaço são oferecidos para a abordagem, alcance, manipulação e uso, independentemente do tamanho do corpo do usuário, postura $\mathrm{e}$ mobilidade.

Para que estes princípios propiciem soluções eficientes nos produtos, Mustaquim (2015) explica que as organizações e os designers devem compreender as necessidades dos usuários, para que a concepção do produto seja bem sucedida para todos, e não apenas para as pessoas com deficiência.

\section{Procedimentos metodológicos}

Os procedimentos metodológicos empregados nesta pesquisa consistiram de enfoque exploratório, abordagem qualitativa e como procedimento técnico foi realizada uma revisão da literatura por meio de levantamento bibliográfico (PRODANOV; FREITAS, 2013; SAMPIERI, COLLADO, LUCIO, 2013). A pesquisa foi organizada em 3 etapas, sendo que a terceira etapa foi subdividida em 2 fases:

- Etapa Descritiva: nessa etapa foi realizada uma revisão da literatura sobre os temas, Design Centrado no Usuário, Usabilidade e Design Universal. Foram levantados e identificados os principais princípios relativos a Usabilidade e Design Universal;

- Etapa Correlacional: os princípios levantados na etapa anterior foram analisados, classificados e associados, ou seja, foram agrupados por semelhança. Essas correlações foram feitas com uso de tabelas, como ferramenta utilizou-se o Microsoft Excel;

- Etapa Explicativa (a): foram atribuídos nomes para os grupos com os princípios agrupados. Esses grupos resultaram nos requisitos para avaliação de produtos. Ainda nesta etapa esses requisitos foram descritos.
- Etapa Explicativa (b): nesta etapa recorreu-se a uma metodologia de projeto, o Guia de Orientação para o Desenvolvimento de Projetos (GODP), para exemplificar em que momentos e de que forma esses requisitos podem ser utilizados em um projeto. Optou-se pelo GODP por este ser um guia que contempla testes com usuários, assim como proposto pelo Design Centrado no Usuário.

Esses procedimentos são ilustrados na Figura 2 a seguir:

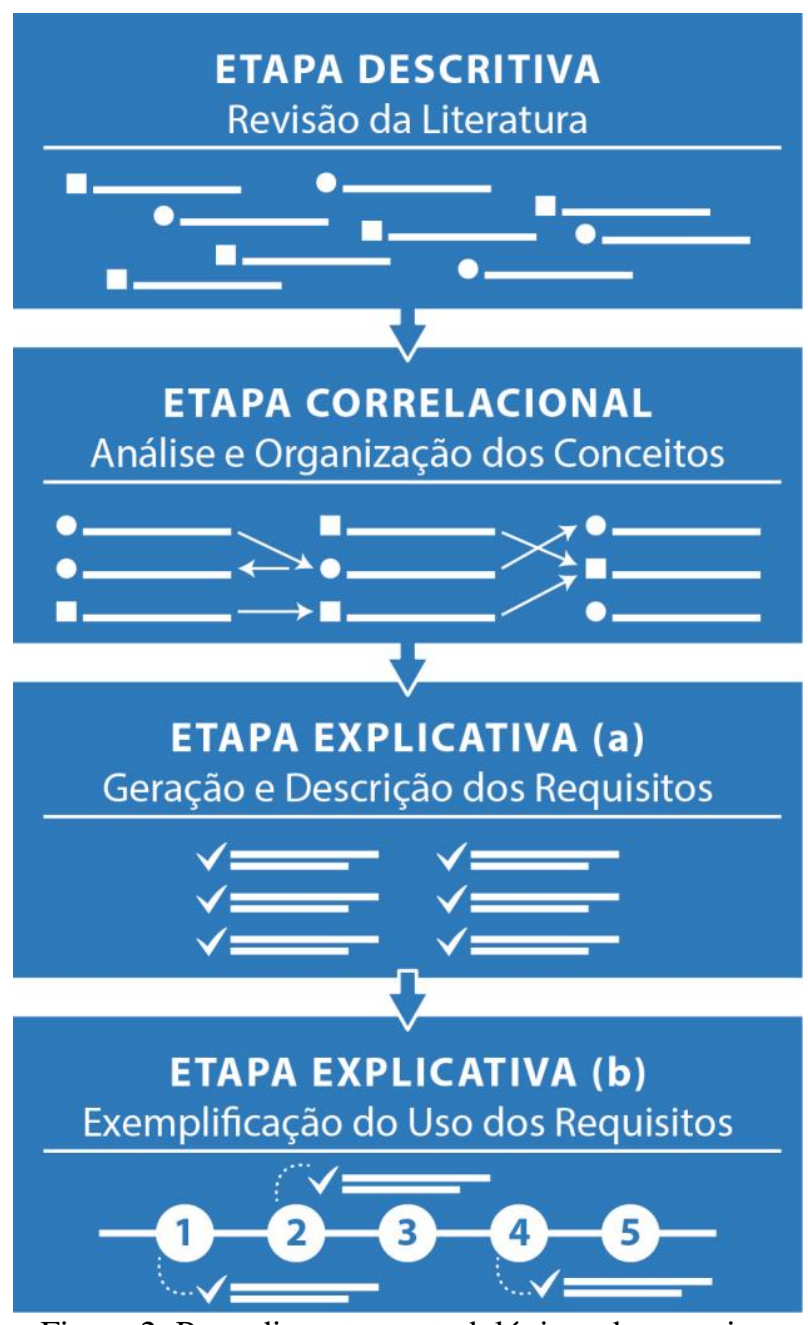

Figura 2: Procedimentos metodológicos da pesquisa. Fonte: Elaborado pelo autor.

O levantamento bibliográfico considerou livros, periódicos da base de dados da Science Direct, normas ISO e ANBT e material online. Dessa forma, o levantamento bibliográfico permitiu 


\section{$16^{\circ}$ \\ ERGODESIGN USIHC CINAHPA}

levantar autores clássicos, material atualizado e normas.

Sobretudo, no que diz respeito a Usabilidade, os princípios levantados foram os propostos por Jordan et al. (1998) e pela norma ISO 9241-11, por serem princípios passiveis de aplicação com projeto de produto. Quanto ao Design Universal, foram utilizados os princípios propostos pelo Center for Universal Design da Universidade do Estado da Carolina do Norte (CONNELL et al., 1997; CUD, 2003).

A metodologia de projeto utilizada para exemplificar o uso dos requisitos consiste em um guia elaborado por Merino (2014), denominado Guia de Orientação para o Desenvolvimento de Projetos (Figura 3).

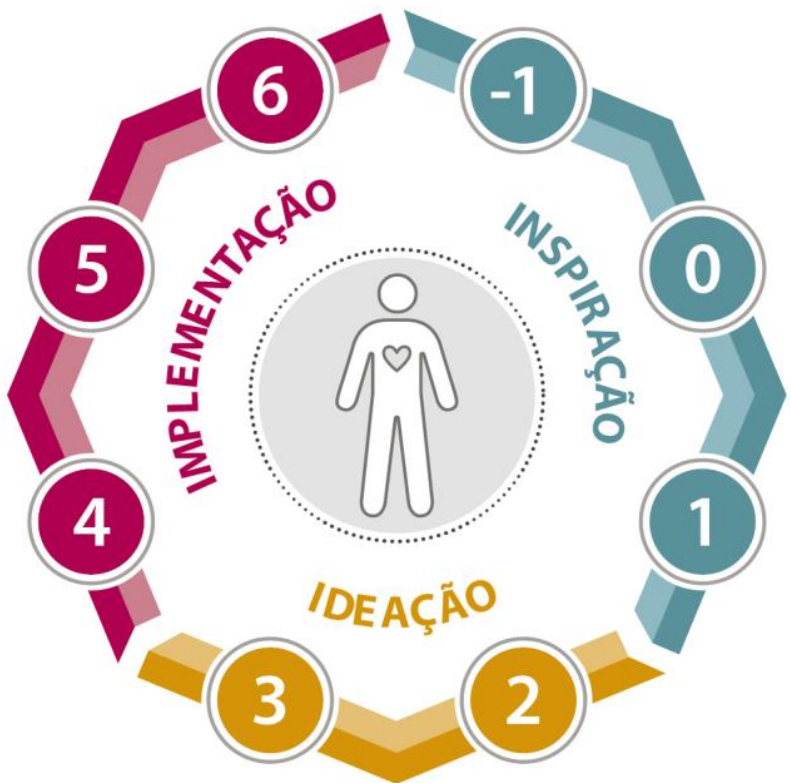

Figura 3: Guia de Orientação para o Desenvolvimento de Projetos. Fonte: Merino (2016).

Este guia contém 8 etapas, divididas em 3 momentos, conforme descritos a seguir (MERINO, 2014; MERINO, 2016):

- Etapa -1 - Oportunidades: essa etapa consiste na verificação de oportunidades de mercado ou em órgãos e fomento, bem como as necessidades de crescimento e demandas para produtos ou setores;

- Etapa 0 - Prospecção: nesta etapa é definida a $16^{\circ}$ Ergodesign - Congresso Internacional de Ergonomia e Usabilidade de Interfaces Humano Tecnológica: Produto, Informações Ambientes Construídos e Transporte

$16^{\circ}$ USIHC - Congresso Internacional de Ergonomia e Usabilidade de Interfaces Humano Computador

CINAHPA | 2017 - Congresso Internacional de Ambientes Hipermídia para Aprendizagem. problemática que norteará o projeto e é verificada a capacidade técnica da equipe que irá desenvolver o projeto;

- Etapa 1 - Levantamento de Dados: trata do levantamento de informações sobre a área a qual se está desenvolvendo o projeto, juntamente ao levantamento de dados sobre necessidades e expectativas dos usuários;

- Etapa 2 - Organização e Análise: a partir dos dados coletados, prossegue-se com sua organização e hierarquização;

- Etapa 3 - Criação: nessa etapa são geradas as alternativas, que são submetidas a análise, utilizando-se de técnicas e ferramentas;

- Etapa 4-Execução: trata do desenvolvimento de protótipos para testes de usabilidade, legibilidade, entre outros;

- Etapa 5 - Viabilização: nessa etapa podem ser realizadas pesquisas junto a consumidores reais ou potenciais consumidores. Podem ser utilizadas ferramentas de avaliação de ergonomia, usabilidade e qualidade aparente;

- Etapa 6 - Verificação Final: nessa etapa são definidas melhorias e novas oportunidades para continuidade do projeto, através da retroalimentação do percurso de design proposto pelo guia.

Os momentos nos quais as etapas estão divididas foram inspiradas no Design Thinking, e, segundo Brown (2008), compreendem 3 estágios pelos quais os projetos de design devem passar, são eles:

- Inspiração: circunstâncias que motivam a busca por soluções, sejam elas problemas, oportunidades ou ambas;

- Ideação: compreende o processo de geração, desenvolvimento e teste de ideias que podem levar a solução de problemas;

- Implementação: este estágio consiste em se traçar um plano para o lançamento do produto no mercado.

Cabe destacar que esta pesquisa faz parte de um projeto maior e foi aprovada pelo Comitê de Ética em Pesquisa com Seres Humanos (CEPSH) da
Realização:

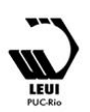




\section{$16^{\circ}$ \\ ERGODESIGN USIHC CINAHPA}

$16^{\circ}$ Ergodesign - Congresso Internacional de Ergonomia e Usabilidade de Interfaces Humano Tecnológica: Produto, Informações Ambientes Construídos e Transporte

$16^{\circ}$ USIHC - Congresso Internacional de Ergonomia e Usabilidade de Interfaces Humano Computador

CINAHPA | 2017 - Congresso Internacional de Ambientes Hipermídia para Aprendizagem.
Universidade Federal de Santa Catarina, atendendo às suas exigências éticas e científicas, com parecer número: 55545815.0.0000.0121.

\section{Resultados}

Os princípios levantados sobre Usabilidade e Design Universal, inicialmente foram organizados em lista para comparação, conforme apresentado na Figura 4, abaixo:

\begin{tabular}{|c|c|}
\hline \multicolumn{2}{|c|}{ CONCEITOS } \\
\hline Usabilidade & Design Universal \\
\hline • Consistência & - Uso Equitativo \\
\hline - Compatibilidade & - Uso Flexível \\
\hline $\begin{array}{l}\text { - Consideração dos } \\
\text { Recursos do Usuário }\end{array}$ & $\begin{array}{l}\text { - Uso Simples e } \\
\text { Intuitivo }\end{array}$ \\
\hline • Retroalimentação & - Informação de Fácil \\
\hline - Prevenção de Erros e & Percepção \\
\hline Recuperação & • Tolerância ao Erro \\
\hline - Controle do Usuário & - Baixo Esforço Físico \\
\hline - Clareza Visual & - Dimensão e Espaço \\
\hline $\begin{array}{l}\text { - Priorização da } \\
\text { Funcionalidade e } \\
\text { Informação }\end{array}$ & $\begin{array}{l}\text { para Aproximação e } \\
\text { Uso }\end{array}$ \\
\hline $\begin{array}{l}\text { Transferência } \\
\text { Adequada de } \\
\text { Tecnologia }\end{array}$ & \\
\hline - Explicitude & \\
\hline
\end{tabular}

Figura 4: Princípios provenientes do levantamento da literatura. Fonte: Elaborado pelo autor.

A formulação dos requisitos, com base nos princípios da Usabilidade e do Design Universal, teve como premissa o agrupamento de princípios que remetem a significados próximos ou que são complementares, conforme apresentado na Figura 5.
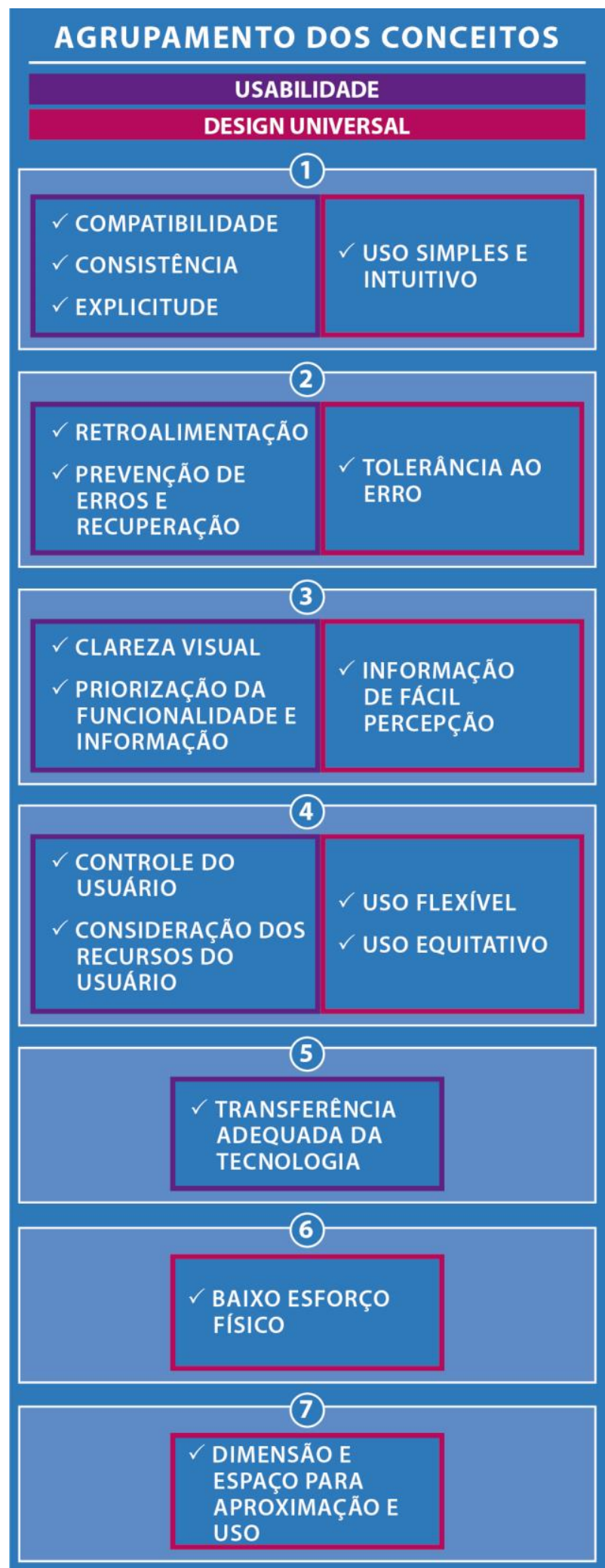

Figura 5: Grupos com os princípios da Usabilidade e Design Universal. Fonte: Elaborado pelo autor.
Realização:

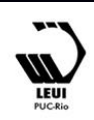




\section{$16^{\circ}$ \\ ERGODESIGN USIHC CINAHPA}

$16^{\circ}$ Ergodesign - Congresso Internacional de Ergonomia e Usabilidade de Interfaces Humano Tecnológica: Produto, Informações Ambientes Construídos e Transporte

$16^{\circ}$ USIHC - Congresso Internacional de Ergonomia e Usabilidade de Interfaces Humano Computador

CINAHPA | 2017 - Congresso Internacional de Ambientes Hipermídia para Aprendizagem.
Devido ao fato de alguns princípios apresentarem significados semelhantes, porém nomenclaturas diferentes (como por exemplo controle do usuário e flexibilidade de uso), optou-se por criar novas denominações ou manter a denominação mais representativa. Após o agrupamento dos princípios que originaram os requisitos, a estes foram atribuídos novas denominações e descrições:

1. Compatibilidade: o uso do produto deve ser coerente com suas funções e forma de operação. As funções devem ser compatíveis com as expectativas do usuário e baseadas em suas experiências com outros produtos e no mundo exterior, sem depender de conhecimento prévio. Devem ser eliminadas complexidades desnecessárias, bem como hierarquizadas as funções por ordem de importância;

2. Advertência: informações que indicam ou alertam uma situação crítica ou perigosa. Devem ser convincentes para que o usuário realize a ação esperada e perceptíveis para serem efetivas. Devem informar sobre os cuidados para não danificar o produto, não fazer uso incorreto, e sobre os riscos potenciais contidos nos produtos. Devem ser localizados em posição visível, o mais próximo possível da fonte de perigo;

3. Comunicação: as informações devem ser de rápida leitura e entendimento, sem causar confusão. As funcionalidades e informações mais importantes devem ser as mais facilmente acessíveis. As informações devem ser comunicadas independente das condições ambientais e das limitações sensoriais dos usuários, para tanto, deve-se utilizar diferentes meios de comunicação (pictórico, verbal, tátil);

4. Adaptabilidade: sempre que necessário o produto deve permitir ajustes para que o usuário o adapte às suas capacidades e limitações. Esses ajustes permitem atender um maior número de pessoas e grupos específicos, no entanto, não devem segregar ou estigmatizar usuários. Mesmo com ajustes e adaptações o produto deve oferecer segurança, conforto, autonomia e um design atraente;

5. Materialização: deve considerar a adequação das características do material em relação ao uso, funcionamento e operação do produto, levando-se em consideração aspectos perceptivos e estético formais. Deve prever questões técnicas e tecnológicas, bem como durabilidade, limpeza, proteção e segurança em relação a proteção do usuário, no que se refere a inflamabilidade, toxidade etc;

6. Força: a avaliação da força diz respeito a adequação de peças e componentes de manejo com a capacidade física do usuário. Essas capacidades estão diretamente relacionadas às características do biotipo, sexo e idade. $\mathrm{O}$ esforço físico inadequado pode comprometer parâmetros como velocidade e grau de precisão na realização das tarefas, bem como comprometer sua segurança;

7. Dimensionamento: corresponde a organização espacial dos elementos que constituem um objeto, em relação aos aspectos de uso, operacionais e perceptivos. Distribuição dos componentes (peças, equipamentos, instrumentos de controle e informações), de forma coerente, harmoniosa, funcional, equilibrada e hierarquizada. Pode acarretar em problemas de uso, de operacionalidade e de percepção.

Com base nesses requisitos, um produto pode ser analisado. Para tanto, recorreu-se ao GODP para exemplificar a forma de se realizar essa avaliação (Figura 6).
Realização:
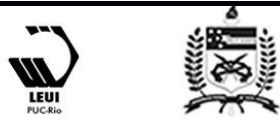

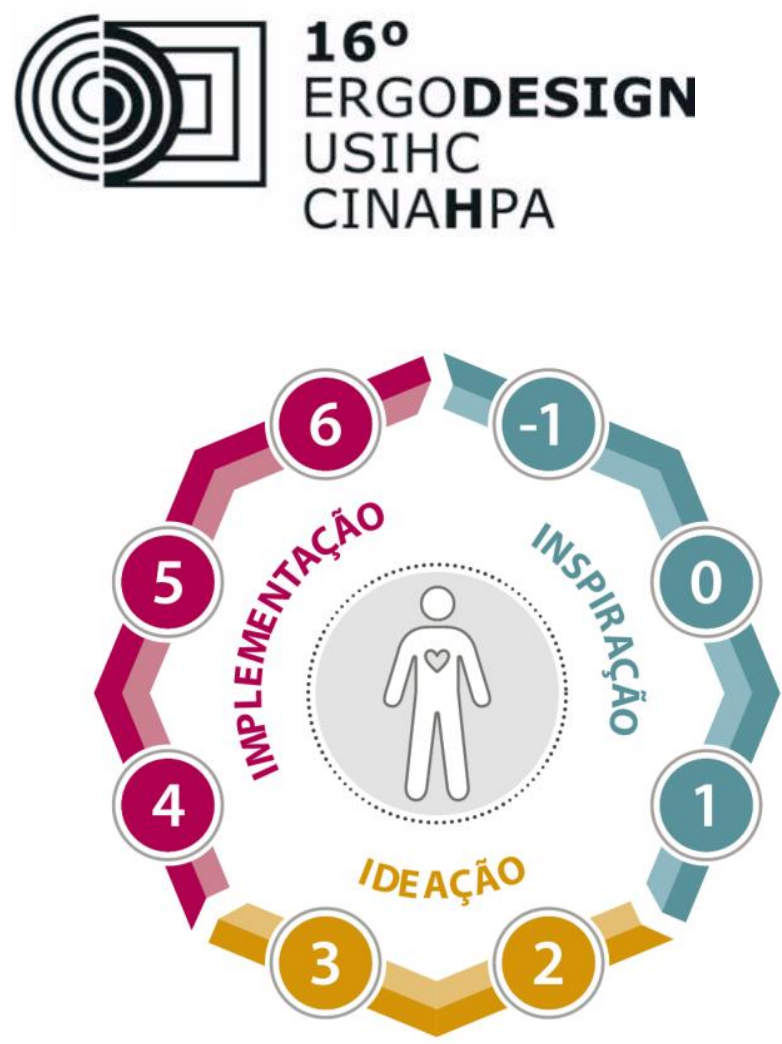

MOMENTO INSPIRAÇÃO

Avaliar concorrentes e similares (tema de projeto).

MOMENTO IDEAÇÃO

Guiar a escolha da melhor alternativa gerada.

\section{MOMENTO IMPLEMENTAÇÃO}

Verificar em situação real o resultado do projeto.

Figura 6: Momentos para análise dos requisitos do produto. Fonte: adaptado de Merino (2016).

Assim, sugere-se que no momento Inspiração, na Etapa 1, os requisitos possam ser utilizados para avaliar produtos concorrentes e similares ao tema de projeto. No momento Ideação, sobretudo na Etapa 3, os requisitos podem ser utilizados para avaliação das alternativas geradas, e por meio de outras ferramentas como por exemplo a matriz de seleção, as alternativas podem ser avaliadas segundo os requisitos e a alternativa julgada mais adequada pode ser implementada. No momento implementação, os requisitos podem ser utilizados para avaliar um protótipo ou modelo funcional em situação real, ou seja, com um usuário específico em um contexto específico de uso.

\section{Considerações Finais}

Conclui-se que mesmo que a incorporação da Ergonomia nos produtos seja considerada difícil e tenha pouca aderência por designers (BAXTER, 2011; GOMES FILHO, 2010), requisitos prédefinidos podem auxiliar no início desse processo, $16^{\circ}$ Ergodesign - Congresso Internacional de Ergonomia e Usabilidade de Interfaces Humano Tecnológica: Produto, Informações Ambientes Construídos e Transporte

$16^{\circ}$ USIHC - Congresso Internacional de Ergonomia e Usabilidade de Interfaces Humano Computador

CINAHPA | 2017 - Congresso Internacional de Ambientes Hipermídia para Aprendizagem.

sobretudo quando proposto juntamente com uma abordagem metodológica que considere momentos para testes do produto com usuários reais.

Dessa forma, a principal contribuição desta pesquisa consiste nos requisitos propostos, que podem ser utilizados em diferentes etapas do desenvolvimento de projetos para análise da adequação ao usuário.

Como continuidade desta pesquisa, pretende-se a incorporação desses requisitos em um modelo de avaliação de produtos, juntamente com requisitos para avaliar o contexto de uso (tarefa, ambiente e usuário).

\section{REFERÊNCIAS}

BAXTER, Mike. Projeto de produto: guia prático para o design de novos produtos. São Paulo: Edgard Blucher, 2011.

\section{BROWN, Tim. Design Thinking: uma} metodologia poderosa para decretar o fim das velhas ideias. Rio de Janeiro: Elsevier, 2010.

\section{CAMBIAGHI, Silvana. Desenho Universal:} métodos e técnicas para arquitetos e urbanistas. São Paulo: Senac, 2012.

CHISHOLM, Wendy; MAY, Matt. Universal design for web applications. 1st ed. Beijing: O'Reilly, 2008.

COLEMAN, Roger; CLARKSON, John; HOSKING, Ian; WALTER, Sam. What is inclusive design. Disponível em:

<http://www.inclusivedesigntoolkit.com/betterdesi gn2/whatis/whatis.html>. Acesso em: 23 fev. 2017.

CONNELL, Bettye Rose; JONES, Mike; MACE, Ron; MUELLER, Jim; MULLICK, Abir;

OSTROFF, Elaine; SANFORD, Jon; STEINFELD, Ed; STORY, Molly; VANDERHEIDEN, Gregg.

The Principles of Universal Design. Center for Universal Design. 1997. Disponível em: <http://www.ncsu.edu/ncsu/design/cud/about_ud/u dprinciplestext.htm>. Acesso em: 23 fev. 2017.

CUD. The Center for Universal Design. A guide to
Realização:
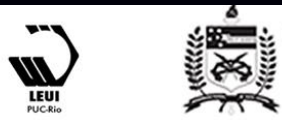


\section{$16^{\circ}$ \\ ERGODESIGN USIHC CINAHPA}

$16^{\circ}$ Ergodesign - Congresso Internacional de Ergonomia e Usabilidade de Interfaces Humano Tecnológica: Produto, Informações Ambientes Construídos e Transporte

$16^{\circ}$ USIHC - Congresso Internacional de Ergonomia e Usabilidade de Interfaces Humano Computador

CINAHPA | 2017 - Congresso Internacional de Ambientes Hipermídia para Aprendizagem. evaluating the universal design performance of products. Raleigh, North Carolina State

University. 2003. Disponível em:

$<$ https://www.ncsu.edu/ncsu/design/cud/pubs_p/do cs/UDPMD.pdf $>$. Acesso em: 23 fev. 2017.

GIACOMIN, Joseph. What is Human Centred Design? $10^{\circ}$ Congresso Brasileiro de Pesquisa e Desenvolvimento em Design, São Luís (MA). 2012.

GOMES FILHO, João. Ergonomia do objeto: sistema técnico de leituras. 2.ed. rev. e ampl. São Paulo: Escrituras, 2010.

HALL-ANDERSEN, L. B., BROBERG, O. Integrating ergonomics into engineering design: The role of objects, Applied Ergonomics, v. 45, n. 3, p. 647-654, 2013.

HOSKING, Ian; CLARKSON, John; COLEMAN,Roger. Why do inclusive design. Disponível em:

<http://www.inclusivedesigntoolkit.com/betterdesi gn2/why/why.html>. Acesso em 23 fev. 2017.

HOSKING, Ian; WALLER, Sam. How to get started. Disponível em:

$<$ http://www.inclusivedesigntoolkit.com/betterdesi gn2/gettingstarted/gettingstarted.html>. Acesso em: 23 fev. 2017.

IIDA, Itiro; GUIMARÃES, Lia Buarque de Macedo. Ergonomia: projeto e produção. 3 ed. revista. São Paulo (SP): Blucher, 2016.

ISO 9241, Parte 11. Orientações sobre

Usabilidade. Associação Brasileira de Normas Técnicas. ABNT, 2011.

ISO 9241, Parte 210. Projeto centrado no ser humano para sistemas interativos. Associação Brasileira de Normas Técnicas. ABNT, 2011.

JORDAN, Patrick W. An Introduction to Usability. London: Taylor \& Francis, 1998.

KRIPPENDORFF, Klaus. Design centrado no usuário: uma necessidade cultural. Estudos em Design, Rio de Janeiro, v. 8, n. 3, p. 87-98, 2000.
LAGATTA, Jessica; NICOLATONIO, Massimo Di; VALLICELLI, Andrea. Design for Inclusion. Differences and Similarities between DfA and UD in the Field of Sailing Yacht. Design, Procedia Manufacturing, V. 3, P. 2714-2721, 2015.

MACE, Ronald L.; HARDIE, Graeme J.; PLACE, Jaine P. Accessible Environments: Toward Universal Design. 1996. Disponível em: <https://www.ncsu.edu/ncsu/design/cud/pubs_p/pu d.htm>. Acesso em: 23 fev. 2017.

MERINO, Giselle Schmidt Alves Díaz. Metodologia para a prática projetual do design: com base no projeto centrado no usuário e com ênfase no design universal. $2014.1 \mathrm{v}$. Tese (Doutorado) - Universidade Federal de Santa Catarina, Centro Tecnológico, Programa de PósGraduação em Engenharia de Produção, 2014.

MERINO, Giselle Schmidt Alves Díaz. GODP Guia de Orientação para Desenvolvimento de Projetos: Uma metodologia de Design Centrado no Usuário. Florianópolis: NGD/UFSC, 2016. Disponível em:

<http://www.ngd.ufsc.br/files/2016/07/e-bookgodp.pdf $>$. Acesso em: 13 mar. 2016.

MORAES, A. Ergonomia e Usabilidade de produtos, programas e informação. In: MORAES, A.; FRISONI, B. C. Ergodesign: produtos e processos. Rio de Janeiro: 2AB, 2001.

MUSTAQUIM, Moyen M. A Study of Universal Design in Everyday Life of Elderly Adults, Procedia Computer Science, v. 67, p. 57-66, 2015.

PREECE, J.; ROGERS, Y.; SHARP, H. Design de interação: além da interação homem-computador. Porto Alegre: Bookman, 2005.

PRODANOV, Cleber Cristiano; FREITAS, Ernani Cesar. Metodologia do Trabalho Científico: Métodos e técnicas da pesquisa e do trabalho acadêmico. Novo Hamburgo: Freevale, 2013.

SAMPIERI, Roberto Hernandez; COLLADO, Carlos Fernández; LUCIO, María del Pilar Baptista. Metodologia de Pesquisa. Porto Alegre:
Realização:

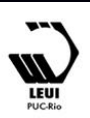




\section{$16^{\circ}$ \\ ERGODESIGN USIHC CINAHPA}

$16^{\circ}$ Ergodesign - Congresso Internacional de Ergonomia e Usabilidade de Interfaces Humano Tecnológica: Produto, Informações Ambientes Construídos e Transporte

$16^{\circ}$ USIHC - Congresso Internacional de Ergonomia e Usabilidade de Interfaces Humano Computador

CINAHPA | 2017 - Congresso Internacional de Ambientes Hipermídia para Aprendizagem.

Penso, 2013.

Vink, Peter; Eijk, D.J. The effect of a participative product design process on user performance, Safety Science, v. 45, n.5, p. 567-577, 2007.

Vink, Peter; Veen, Sigrid. Can Prior Experience Influence Seating Comfort Ratings? SAGE Journals, v. 24, n. 2, p. 16-20, 2016.

WALLER, Sam; CLARKSON, John. Inclusive design toolkit: Framework. Disponível em: $<$ http://www.inclusivedesigntoolkit.com/betterdesi gn2/UCframework/framework.html>. Acesso em: 23 fev. 2017.

\section{Agradecimentos}

À Coordenação de Aperfeiçoamento de Pessoal de Nível Superior (CAPES), ao Conselho Nacional de Desenvolvimento Científico e Tecnológico (CNPq), ao Programa de Pós-Graduação em Design e Expressão Gráfica (PPGDEG/UFSC), ao Núcleo de Gestão de Design da Universidade Federal de Santa Catarina (NGD/UFSC), que viabilizaram esta pesquisa. 